Original Article, Endocrine

\title{
Association between PTPN22 C1858T Gene Polymorphism and Graves' Disease in Egyptians, Correlation with Tc-99m Pertechnetate Thyroid Uptake
}

\author{
Abougabal, $M^{1}$.Farghly, $M^{2}$.Al-Gabarty, $S^{2}$. El-Abd $D^{\mathbf{2}}$. \\ ${ }^{1}$ Nuclear Medicine Unit (NEMROCK), ${ }^{2}$ Clinical and Chemical Pathology \\ Departments, Kasr Al- Ainy Hospital, Cairo University, Egypt
}

\section{ABSTRACT:}

Background: The protein tyrosine phosphatase non receptor 22 gene (PTPN22) is an important negative regulator of signal transduction through the T-cellreceptors (TCR). A single-nucleotide polymorphism (SNP) C1858T within this gene was shown to be a risk factor for several autoimmune diseases such as Graves'disease (GD). Objective: The aim of this study was to analyze the possible association between C1858T SNP of protein tyrosine phosphatase non receptor type 22 (PTPN22) and GD in Egyptian patients and to correlate this gene expression with Tc-99m Pertechnetate uptake value and thyroid hormonal profile. Patients and Methods: The current study evaluated the PTPN22 C1858T polymorphism in 40 GD patients and 20 healthy age and sex matched control subjects with no family history of GD or any other autoimmune disease. Genotyping was performed by polymerase chain reaction-restriction fragment length polymorphism

(RFLP).Tc-99m

Pertechnetate thyroid scan and uptake was performed for GD patients. Thyroid hormonal profile including serum FT3, FT4 and TSHwas also performed for patients and control subjects.Results: No statistical significant difference in the distribution of genotypes and allelefrequency for the PTPN22 C1858T SNP between GD patients and controls $(P$ $>0.05)$. Genotype analysis revealed that all control group and 36/40 GD patients had the CC genotype while only 4 GD patients hadthe TT genotype. Patients with TT genotype had a significantly higher uptake $\%$ when compared with that of patients with CC genotype $(26.2 \pm 11.5 \%$ versus $9.2 \pm 3.1 \%$, respectively $\quad(P<0.001)$. Conclusion: No association was found between the PTPN22 C1858T polymorphism and Graves' disease in Egyptian patients. However, preliminary data suggest that the expression of TT genotype together with high Tc-99m uptake percent might be a predictor for refractory disease that would necessitate more aggressive treatment.

Key Words: Graves' disease, Protein Tyrosine Phosphatase Non Receptor Gene 22,SingleNucleotide Polymorphism, Tc-99m Thyroid Uptake, Thyroid Hormonal Profile.

Corresponding Author: Abougabal, M E-mail:kodomojanai20@yahoo.com 


\section{INTRODUCTION:}

Graves' disease (GD), the most frequent form of autoimmune thyroid disease (AITD), is triggered by the combination of genetic susceptibility and environmental encounters ${ }^{[1]}$. Several factors can influence a person's susceptibility for GD. Females are much more likely to contract the disease than males, racial factors as White and Asian populations are at higher risk than black populations ${ }^{[2]}$. Genetic factors are important, but not determinative for predisposition to GD, the most important allele in British Caucasians implicated in disease predisposition is HLA CLASS 11 alleles DRB1-0304, DQB1-02 and DQA1$0501^{[3]}$.Among multiple non-HLA genes involved in autoimmunity regulation, cytotoxic T-lymphocyte-associated antigen 4 (CTLA-4), tumor necrosis factor (TNF) and protein tyrosine phosphatase non receptor gene (PTPN22) are the most important ${ }^{[4]}$.PTPN22 gene located on chromosome 1p13, encodes the lymphoid tyrosine phosphatase (LYP), which is expressed exclusively in hemopoietic cells ${ }^{[5]}$. In $\mathrm{T}$ cells, LYP is an important negative regulator of signal transduction through the T-cell receptor (TCR) and forms a complex with the negative regulatory kinase C-SRC kinase (Csk). The C1858T variation causes the substitution of an Arg with a Trp in position 620 (R620W), which is located in the LYP-Csk interaction motif. The Arg 620 Trp substitution strongly reduces the affinity of LYP for $\mathrm{Csk}^{[6]}$. An association of PTPN22 (R620W) polymorphism was reported first with many autoimmune diseases like type 1 Diabetes Mellitus (T1DM),rheumatoid $\operatorname{arthritis}^{[7]}$, Graves' disease ${ }^{[8]}$, systemic lupus erythematosus ${ }^{[9]}$ and generalized vitiligo $^{[10]}$.
Diagnosis of GD was based on documented clinical and biochemical evidence of hyperthyroidism, diffuse goiter, and the presence of at least one of the following: positive thyrotrophin receptor antibody (TRAb) tests, diffusely increased I-131 or Tc-99m pertechnetate uptake in thyroid gland, or presence of exophthalmos ${ }^{[11,12]}$.

The aim of this work was to study the association of protein tyrosine phosphatase non receptor type 22 (PTPN22) C1858T gene polymorphism with Graves' disease among Egyptian patients and to correlate this gene expression with Tc-99m pertechnetate uptake value.

\section{PATIENTS AND METHODS:}

This prospective study was conducted on 60 Egyptian individuals who were referred to the thyroid clinic in the nuclear medicine department in Kasr Al-Ainy Hospital, Cairo University to perform routine Tc$99 \mathrm{~m}$ thyroid scintigraphy and/or to seek medical advice to receive therapeutic doses of Iodine-131.Individuals were divided into two groups; group 1 included 40 patients with known history of Graves' disease (11 males and 29 females), with mean disease duration of $2.2 \pm 1.1$ years (range 0.5-4.0 years); mean age $35.8 \pm 8.6$ years. Diagnosis of GD was based on documented clinical and biochemical evidence of hyperthyroidism, diffuse goiter, and thepresence of diffuse increased Tc-99m pertechnetate uptake in the thyroid scan $^{[11,12]}$. All patients classified as GD were examined for history of disease duration, details of drug intake and course of the disease activity. GD Patients with family or previous history of any associated other autoimmune disease were excluded from the study. Group 2 included 20 
healthy age and sex matched controls (5 males and 15 females), with mean age $31.8 \pm 9.2$ years, from healthy blood donors with no family history of GD or any other types of autoimmune disorders. All subjects in the study signed written informed consent and the study had been approved by the institutional ethics committee. Patients and controls were further subjected to the following:

1- Genomic DNA extraction and analysis for PTPN22 gene polymorphisms(C1858T) using PCR followed by restriction fragment length polymorphism (RFLP) analysis.

2- Analysis of serum TSH, FT3 and FT4 by electro-chemiluminecence method on (Elecsys) system (Roch Diagnostic Gmbh, Sandhofer 116, D-68305 Mannheim).Blood samples were measured in the laboratory of the clinical and chemical pathology department in Kasr Al-Ainy hospital .

3-Technetium-99m (Tc-99m) pertechnetate thyroid scan and uptake (for only patients in group 1): Patients under antithyroid treatment were instructed to stop it 5 days before the scan. Tc- $99 \mathrm{~m}$ pertechnetate was injected in a dose of $185 \mathrm{MBq}(5 \mathrm{mCi})$ through intravenous line in the upper limb followed by saline wash. Patients positioned supine under the gamma camera (Philips-Axis, Eindhoven, the Netherlands) mounted with a low-energy, parallel-hole collimator, $20 \%$ energy window centered at $140 \mathrm{KeV}, 256 \times 256$ matrix for static images and zoom 2.65. Static images of the syringes before and after injection for 1 minute were obtained. Anterior static images of the neck for 500,000 counts, 20 minutes post-injection were acquired with the neck extended to the closest distance from the collimator. Thyroid uptake values were estimated automatically using the pre and post syringe calculated method (uptake values $>4 \%$ were considered abnormal in our institution).

Statistical Analysis Data were statistically described in terms of mean and standard deviation, median and range or frequencies (number of cases) and percentages when appropriate. Comparison of numerical variables between the study groups was performed using Student's ttest for independent samples. Comparison of numerical variables was performed using paired $t$-test. $P<0.05$ was considered to be statistically significant. Association between qualitative data was done using Chi Square $\left(X^{2}\right)$ test. Correlation between various variables was done using Pearson moment correlation equation. All statistical calculations were performed using computer programs SPSS (Statistical Package for the Social Science; SPSS Inc., Chicago, IL,(USA) version 15 for Microsoft Windows.

\section{RESULTS:}

The two studied groups (GD patients and controls) were age and sex matched (Table 1).GD patients group had statistically significant difference when compared with the control group as regards mean serum levels of TSH, FT3, FT4 (Table 1).Comparison of the distribution of genotypes and allele frequency for the PTPN22 C1858T polymorphism showed no statistically significant difference between GD patients and controls. Moreover, the genotype analysis revealed that $90 \%$ of GD patients $(36 / 40)$ were of the CC genotype while the rest10\%(4/40) had the TT genotype. Whereas, all controls (100\%)had CC genotype. C/T genotype was not found among all studied individuals (Table1). 
Table 2 represents patient's characteristics, thyroid hormonal profile and Tc-99m thyroid uptake \% with comparison between $\mathrm{CC}$ and TT genotypes patients. Patients with TT genotype had a significantly higher uptake $\%$ when compared with that of patients with CC genotype(Table 2, Fig. 1). Patients with TT genotype $(N=4)$ had relatively longer disease duration of (median2.8 years). Throughout the course of the disease, they were complaining of severe symptoms of hyperthyroidism that were not responding to full doses of medical treatment in the form of $60 \mathrm{mg}$ carbimazole. They also received therapeutic doses of radioactive iodine-131 therapy (two patients received single dose of $15 \mathrm{mCi}$ and the other two patients received two therapeutic doses with a total of 27 and $30 \mathrm{mCi}$ ). All had recurrent toxicity at variable times during follow up and they were scheduled for other therapeutic doses of I-131 at the time of presentation in the current study.

Pearson's test for GD patients showed no significant correlation between Tc-99m Thyroid uptake $\%$ and other studied parameters including age, disease duration and serum TSH level $(R=0.034,-0.096$, 0.164 , respectively; $P>0.05)$. Figure 2 demonstrates a thyroid scan of a female patient with TT genotype and resistant thyrotoxicosis for 3 years in spite of medical treatment and total I-131 therapeutic dose of $27 \mathrm{mCi}$.

Table (1): Demographic data, thyroid hormonal profile and Genotype analysis of the two studied groups.

\begin{tabular}{|l|l|l|l|}
\hline & $\begin{array}{l}\text { GD!Patients } \\
(\mathrm{n}=40) \\
\text { Mean } \pm \text { SD } \dagger\end{array}$ & $\begin{array}{l}\text { Control } \\
(\mathrm{n}=20) \\
\text { Mean } \pm \text { SD }\end{array}$ & P* \\
\hline Age $(\mathrm{yr})$. & $35.8 \pm 8.6$ & $31.8 \pm 9.2$ & $>0.05$ \\
\hline $\begin{array}{l}\text { Sex } \\
\text { Male }\end{array}$ & $11(27.5 \%)$ & $\begin{array}{l}5(25 \%) \\
15(57 \%)\end{array}$ & $>0.05$ \\
Female & $29(72.5 \%$ & $3.2 \pm 0.9$ & \\
\hline Thyroid Hormones & $17.6 \pm 7.8$ & $1.4 \pm 0.3$ & $<0.05$ \\
FT3(pg/ml) & $5.1 \pm 2.1$ & $3.1 \pm 1.3$ & $>0.05$ \\
FT4(ng/dl) & $0.02 \pm 0.01$ & $20(100 \%)$ & \\
\hline TSH( $\mu$ IU/L) & $36(90 \%)$ & 0 & \\
\hline PTPN22 $\dagger \dagger$ Genotypes & $4(10 \%)$ & & \\
CC & TT & & \\
\hline
\end{tabular}

! GD Graves' disease.

$\uparrow$ SD Standard Deviation of mean.

$* P$ is significant if $<0.05$.

$\dagger \dagger$ Protein tyrosine phosphatase non receptor 22 gene. 
Table (2): Characteristics, thyroid hormonal profile and thyroid uptake \% in GD patients with comparison between $\mathrm{CC}$ and TT genotypes.

\begin{tabular}{|c|c|c|c|}
\hline & $\begin{array}{l}\text { GD! Patients with } \\
\text { CC genotype } \\
(n=36)\end{array}$ & $\begin{array}{l}\text { GD Patients with } \\
\text { TT genotype } \\
(n=4)\end{array}$ & $\mathrm{P}^{*}$ \\
\hline Age $($ year $)($ Mean $\pm \mathrm{SD} \dagger)$ & $35.4 \pm 8.2$ & $39.5 \pm 12.5$ & $>0.05$ \\
\hline Disease Duration (yr.)(Median) & 1.8 & 2.8 & $>0.05$ \\
\hline $\begin{array}{l}\text { Clinical data } \\
\text { - No. }(\%) \text { of pt. with severe } \\
\text { thyrotoxicosis } \\
\text { - No. }(\%) \text { of pt. with exophthalmos } \\
\text { - No. }(\%) \text { of patients received I-131 } \\
\text { therapy }\end{array}$ & $\begin{array}{l}16(44.4) \\
10(27.8) \\
12(33.3)\end{array}$ & $4(100)$ & - \\
\hline $\begin{array}{l}\text { Thyroid Hormones } \\
\text { - FT3 } \uparrow(\mathrm{pg} / \mathrm{ml}) \\
\text { - FT4 } \uparrow \dagger(\mathrm{ng} / \mathrm{dl}) \\
\text { - TSH } \uparrow \dagger \dagger(\mu \mathrm{IU} / \mathrm{L})\end{array}$ & $\begin{array}{l}16.9 \pm 7.5 \\
4.9 \pm 2.0 \\
0.022 \pm 0.018\end{array}$ & $\begin{array}{l}13.2 \pm 0.9 \\
5.7 \pm 0.3 \\
0.01 \pm 0.00\end{array}$ & $>0.05$ \\
\hline Tc-99m Thyroid uptake $\%($ Mean \pm SD) & $9.2 \pm 3.1$ & $26.2 \pm 11.5$ & $<0.001$ \\
\hline
\end{tabular}

! GD Graves' disease.

$\uparrow$ SD Standard Deviation of mean.

$* P$ is significant if $<0.05$.

$\uparrow$ FT3Free triiodothyronine.

$\dagger \dagger$ FT4 Free tetraiodothyronine.

$+\dagger \dagger$ TSH Thyroid stimulating hormone. 


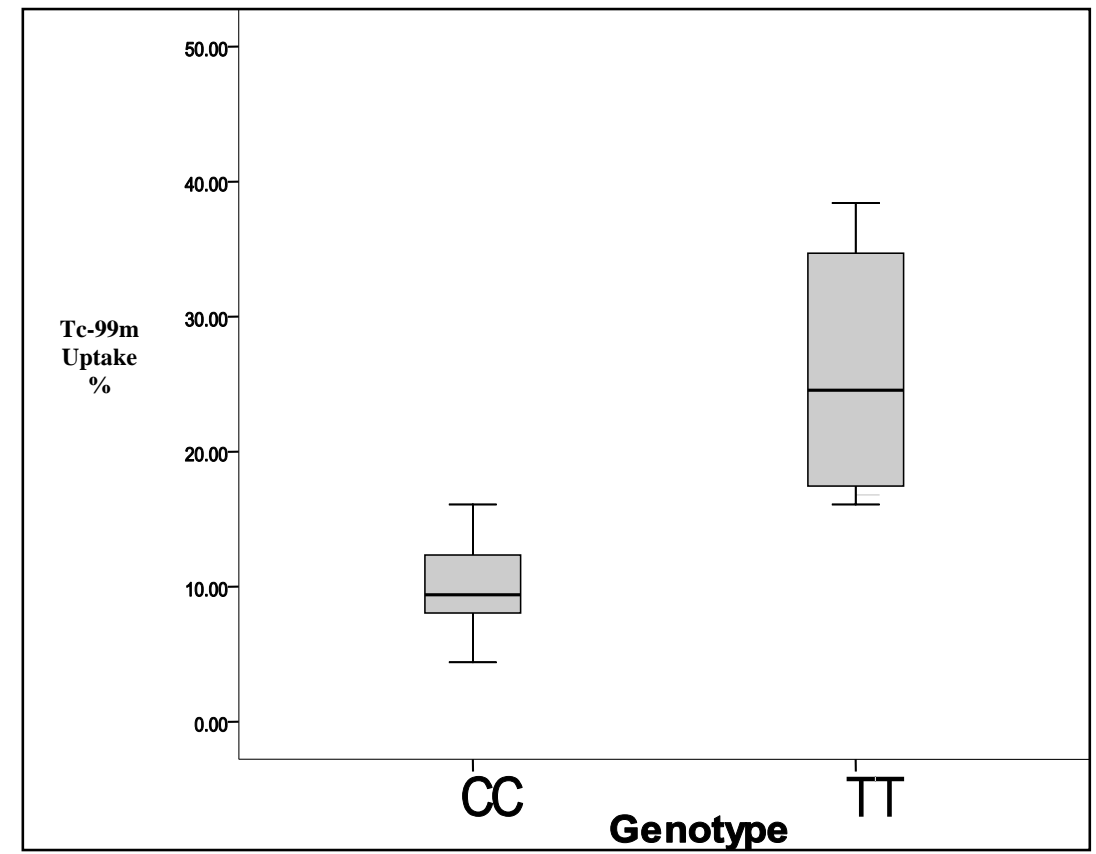

Figure (1): Box and Whisker plot of Tc-99m Thyroid uptake \% in the two PTPN22 genotypes of the GD group. TT patients $(N=4)$ had significantly higher uptake $\%$ than CC patients $(N=36)(P<0.001)$.

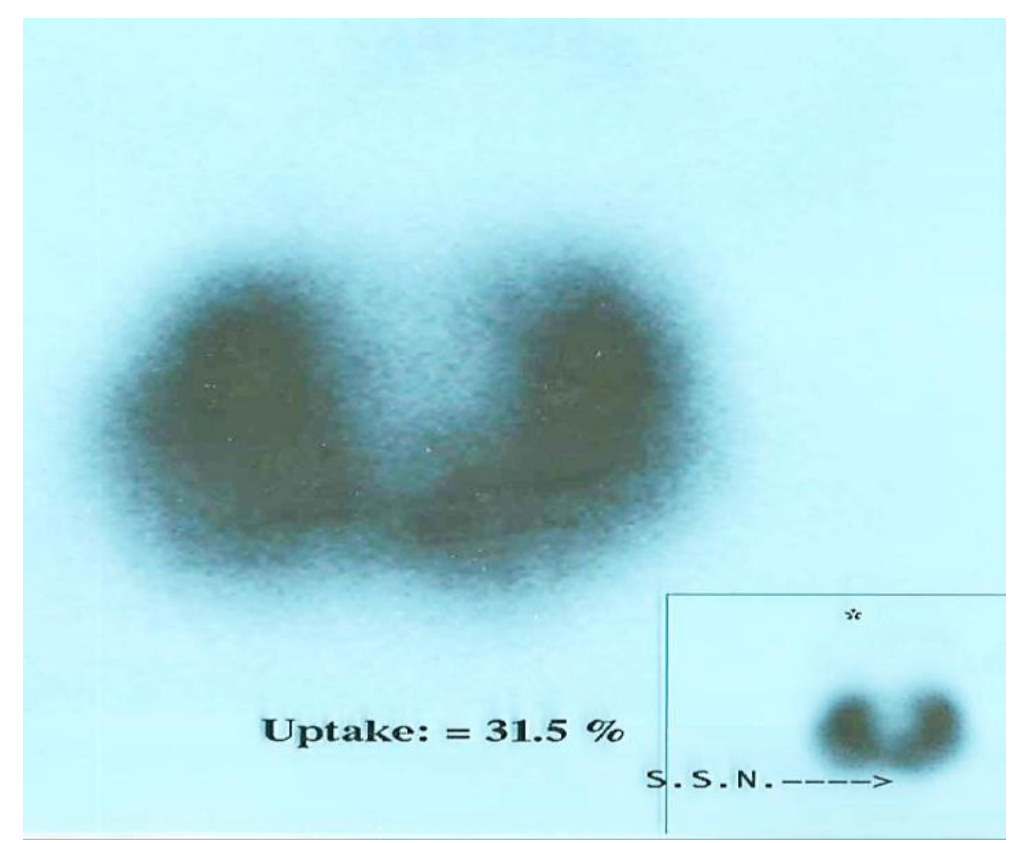

Figure (2): Tc-99m pertechnetate thyroid scan of a female patient, 35 year old with TT genotype. Scan features show diffusely enlarged thyroid gland with intense uniform tracer uptake and diminished extra thyroidal background activity as well as very high uptake value $31.5 \%$. S.S.N. referred to marker opposite the suprasternal notch. 


\section{DISCUSSION:}

Graves' disease (GD) may be related to both genetic and environmental factors that appear to be associated with the development of the disease; a clear genetic susceptibility to GD has been established $^{[13]}$.

A functional single nucleotide polymorphism (SNPs) of the gene encoding protein tyrosine phosphatase type 22 (PTPN22 C1858T; R620W rs2476601) has been described as a strong common genetic risk factor for human autoimmune diseases $^{[7]}$.

This work aimed to study the association of PTPN22C1858T gene polymorphism withGD and to correlate this gene expression with Tc-99m pertechnetate uptake and thyroid hormonal profile. This preliminary study was considered the first pilot study among Egyptian patients with GD.

In the current study, no significant difference was detected in SNPs gene expression between GDpatients and control group $(P>0.05)$. This finding was similar toHeward et al, who did not find an association of any of the individual SNPs of PTPN22 C1858T gene with GD in their United Kingdom population ${ }^{[14]}$. Also, Chabchoub et al stated that SNPs had no or minor effect on autoimmune thyroid disease susceptibility in the Tunisian population $^{[15]}$. These data suggest that the association of SNPs within the PTPN22 region varies between different autoimmune diseases, occurring as part of a haplotype, indicating that the mechanisms by which PTPN22 confers susceptibility to GD may, in part, be disease specific.

On the other hand, the association between a PTPN22 C1858T SNPs and GD was reported by other studies in Japanese (16) and in Russian population ${ }^{[17]}$. Yet, they recommended further studies including functional analysis to confirm their results. Analysis of genotype in our population revealed that all control subjects and 36/40 of GD patients had CC genotype while only 4 GD patients had TT genotype. Taking in consideration the small sample size in the current study, none of our subjects had $\mathrm{C} / \mathrm{T}$ genotype in their allele. Our data agreed with Zhao et al, who did not find $\mathrm{C} / \mathrm{T}$ genotype in Xuzhou and southern China population but they found $\mathrm{C} / \mathrm{T}$ genotype in Chinese Han population and Shandong population. They finally suggested that the susceptibility variants of the PTPN22 SNPs gene varied between the different geographic populations with $\mathrm{GD}^{[11]}$.

The current study revealed that Tc-99m uptake \% was significantly higher in the TT genotype compared to $\mathrm{CC}$ genotype $(P<0.001)$. On the other hand, no significant difference was found between $\mathrm{CC}$ and TT genotype in relation toserum FT3, FT4 and TSH. Our result agrees with Heward et al, who found no correlation between genotypes and biochemical severity of thyroid dysfunction at diagnosis determined from serumlevel of FT4 ${ }^{[14]}$.

There was no direct association between SNPs gene expression and GD that may be attributed to the small sample size and the absence of $\mathrm{C} / \mathrm{T}$ genotype in our sample size. However, further future research in depth is needed to investigate the existence of TT allele in four patients encountered in our study with uncontrolled GD,resistant to both medical treatment and radioactive iodine therapy. This finding raises the querythat the presence of TT genotype might be a direct cause of refractory 
response to antithyroid medical treatment or would be a useful predictor of GD patients who might need more aggressive treatment from the start or may necessitate the introduction of new strategies for specific treatment. Gene therapy in the form of selective small-molecule inhibitor of PTPN22 could be used as a treatment for autoimmunity by reverting the gain-offunction effect of $1858 \mathrm{~T}$ and, restoring normal levels of TCR signaling inautoimmune patients carrying this variation $^{[18]}$.

In view of small number in this pilot study, we recommend more researches including larger patients group to gain greater insight into potential usefulness of PTPN22 gene in patients with GD to study the effect of PTPN22 C1858T polymorphism on T-cells proliferation and cytokine production by lymphocytes. Furthermore, it will be interesting to studythe gene-environment interactions like smoking and tocorrelate the presence of C1858T allele with GD

\section{REFERENCES:}

1- De Groot LJ, Shin YH, Pan D, Gopalakrishnan $G$ and Hennessey JV. Evaluation of $\mathrm{T}$ cell stimulation by thyrotropin-receptor epitopes in Graves' disease. J Endocrinol Invest. 2009; 32 (1):52-6.

2- Manji N, Carr-Smith JD, Boelaert K, et al. Influences of age, gender, smoking, and family history on autoimmune thyroid disease phenotype. J ClinEndocrinolMetab. 2006; 91 (12): 4873-80.

\section{3- Heward JM, Allahabadia A, Daykin} $\mathbf{J}$, et al. Linkage disequilibrium between the human leukocyte antigen class II region of the major development and progression by measuring the serum level of Graves' related autoantibodies.

\section{CONCLUSION}

The current initial study revealed that PTPN22 1858T gene polymorphism has no direct association with Graves' disease among Egyptian patients. Our preliminary data suggest that the expression of TT genotype together with high Tc-99m uptake percent might be a predictor for refractory disease that could necessitate more aggressive treatment.

\section{DISCLOSURE}

The authors indicate no potential conflicts of interest.

\section{ACKNOWLEGEMENTS}

The authors thank Dr. Ahmed Kandeel for helpful contributions to the statistical and grammatical aspects of this work.

histocompatibility complex and Graves' disease: replication using a population case control and familybased study. J ClinEndocrinolMetab. 1998; 83 (10): 3394-7.

4- Correa PA, Gomez LM, Cadena J and Anaya JM. Autoimmunity and tuberculosis. Opposite association with TNF polymorphism. J rheumatol. 2005; 32 (2):219-24.

5- Cohen S, Dadi H, Shaoul E, Sharfe N, Roifman CM. Cloning and characterization of a lymphoid-specific, inducible human protein tyrosine phosphatase. Blood. 1999;3:2013-24. 
6- Cloutier JF, Veillette A. Cooperative inhibition of $\mathrm{T}$-cell antigen receptor signaling by a complex between a kinase and a phosphatase. J Exp Med. 1999; 189 (1):111-21.

7- Bottini N, Musumeci L, Alonso A, et al. A functional variant of lymphoid tyrosine phosphatase is associated with type I diabetes. Nat Genet. 2004; 36 (4): 337-8.

8- Skórka, A, Bednarczuk T, BarAndziak, E, Nauman J, Ploski R. Lymphoid tyrosine phosphatase (PTPN22/LYP) variant and Graves' disease in a Polish population: association and gene dose-dependent correlation with age of onset. ClinEndocrinol. 2005; 62 (6):679-82.

9- Reddy MV, Johansson M, Sturfelt G, et al. The R620W C/T polymorphism of the gene PTPN22 is associated with SLE independently of the association of PDCD1. Genes Immun.2005; 6 (8): 658-62.

10- Canton I, Akhtar S, Gavalas NG, et al. A single-nucleotide polymorphism in the gene encoding lymphoid protein tyrosine phosphatase (PTPN22) confers susceptibility to generalized vitiligo. Genes Immun. 2005;6 (7): 584-7.

11-ZhaoSX, Pan CM, Cao HM, et al. Association of the CTLA4 gene with Graves' disease in the Chinese Han population. PloS one. 2010;5 (3):e9821.

12-Song HD, Liang J, Shi JY, et al. Functional SNPs in the SCGB3A2 promoter are associated with susceptibility to Graves' disease. Hum Mol Genet. 2009;18(6):1156-70.

13- Jacobson EM, Tomer Y. The genetic basis of thyroid autoimmunity. Thyroid. 2007; 17(10):949-61.

14- Heward JM, Brand OJ, Barrett JC, Carr-Smith JD, Franklyn JA, Gough SC. Association of PTPN22 Haplotypes with Graves' disease. J ClinEndocrinolMetab. 2007;92 (2):68590 .

15- Chabchoub G, Teixiera EP, Maalej A, et al. The R620W polymorphism of the protein tyrosine phosphatase 22 gene in autoimmune thyroid diseases and rheumatoid arthritis in the Tunisian population. Ann Hum Biol. 2009;36 (3): 342-9.

16- Ichimura M, Kaku H, Fukutani T, et al. Associations of protein tyrosine phosphatase non receptor 22 (PTPN22) gene polymorphisms with susceptibility to Graves' disease in a Japanese population. Thyroid.2008; 18 (6): 62530.

17-Zhebrun D, Kudryasbova Y, Babenko A, et al. Association of PTPN22 1858T/T genotype with type 1 diabetes, Graves' disease but not with rheumatoid arthritis in Russian Population.Aging. 2011;3 (4):368-73.

18-Vang T, Congia M, Macis MD, et al. Autoimmune-associated lymphoid tyrosine phosphatase is a gain-offunction variant. Nat genet. 2005;37 (12):1317-9. 